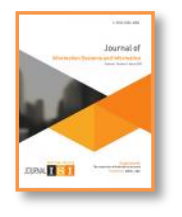

Vol. 2, No. 2, September 2020 e-ISSN: 2656-4882 p-ISSN: 2656-5935

http://journal-isi.org/index.php/isi

Published By DRPM-UBD

\title{
Translator Mobile App for Teaching Children of Beginner-Level -French
}

\author{
Alina NEPEMBE ${ }^{1}$, Leena KLOPPERS 2 , Jude OSAKWE ${ }^{3}$ \\ ${ }^{1}$ Department of Informatics, Namibia University of science and Technology \\ ${ }^{2}$ Department of Technical and Vocational Education and Training, Namibia University of science \\ and Technology \\ 32Department of Informatics, Namibia University of science and Technology \\ Email: ambeliz93@gmail.com¹, 1kloppers@nust.na², josakwe@nust.na ${ }^{3}$
}

\begin{abstract}
Living in the digital era and in a society that recognizes the importance of technology, Information and Communications Technology (ICT) plays a major role in almost every point of life and particularly in education. Teachers play a major role in the teaching and learning of foreign languages. Mobile applications open new opportunities for learning how to read and speak different languages. One such mobile application that is used in education to facilitate learning of new language is the mobile translator. Although, there are numerous language translator applications that are freely available online, most of them have different shortcomings. This study focused on filling the gap of different shortcomings presented by different translator applications and specifically cater the mobile application for the FNCC curriculum. The main objective of this study was to design and develop a mobile translator application to facilitate the effective teaching of beginner level French for children at FNCC. Interviews were carried out as a data collection method to identify the requirements for the mobile translator application. The French teachers at the FNCC (Franco Namibia Cultural Centre) served as a sample group. Purposive sampling method was used to identify the participants and two teachers were selected. The application was developed following the incremental process model, an android mobile application was designed and developed, the application was evaluated using the PACMAD usability model, the incremental testing was adopted. The findings of the research show that there are different teaching strategies used in teaching and learning of French. Features were incorporated on the mobile application that are believed to enhance teaching and learning of French at beginner level. The PACMAD usability model determined what other French applications (which were purposively selected) lack and a comparison was carried out between the selected applications. The results of the comparison determined what should be included in the French mobile application for beginner level for children at the FNCC.
\end{abstract}

Keywords: Mobile applications, translator's applications, French language teacbing and learning, FNCC

This work is licensed under a Creative Commons Attribution 4.0 International License. 


\section{INTRODUCTION}

Information and Communications Technology (ICT) plays a major role in almost every point of life and particularly in education [1]. The use of ICT in education, including language teaching and learning, is seen as a positive response to the development of ICT in the current millennium [2]. Mobile technology has recently become one of the most important areas of research in the field of teaching and learning [3]; [4]; [5]. This is because learners own and use mobile technology day-to-day, in recreational and educational activities [6]. The authors further state that in this way, mobile technologies contribute to a teaching/learning process more motivating and personalised.

Mobile applications can open up new opportunities for learning how to read and speak different languages [7]. One such mobile application that is used in education to facilitate learning of new language is the translator application (app) [8]. Although there are books available for new learners to speak new languages it takes time for them to understand the language. Furthermore, it takes lot of practice to get good pronunciation of the words before they will be able to converse fluently [9]. The authors further argue that translation apps help learners easily relate new information to old information and reduce learning anxiety. This view is supported by the findings of a study [8] where translator applications were continuously shown to be effective as a teaching aid for learners to learn a new language and to pronounce words.

[10] summarizes the added value of using translators as tools that can help students learn foreign languages easily; check whether their comprehension is accurate; simplify memory limitations in memorising new words, grammar, and sentence structures; it can also help students develop and express themselves in a different language; and it enhances motivation to learn a new foreign language.

\section{OBJECTIVES}

Main research objective:

Design and develop a mobile translator application to facilitate the effective teaching of beginner level French for children at FNCC.

Sub-objectives:

In order to achieve the main objective, the following sub-objectives are drawn:

1. examine the teaching and learning strategies used by the teachers to facilitate the learning of French for children at beginner level;

2. identify the features of a mobile translator app that can enhance the teaching and learning of French for children at beginner level;

3. evaluate the suitability of the developed mobile translator app to enhance teaching and learning of French for children at beginner level 


\section{METHODOLOGY}

For this research interpretivism philosophy has been followed as it is qualitative. Qualitative research methods such as participant-observation, unstructured interviews, direct observation, describing records are most used for collecting data [11]. During the data collection, the researchers interact with the participants directly such as it happens while data collection through interviews. Interviewing the teachers was selected because it allows the interviewer to capture accurate and more data, with reference to the research questions, accurate and more information is required from the teachers in order to develop the mobile application. In this study the target population is the French teachers at FNCC for children at beginner level. Purposive sampling method was selected for this study. The selection of the interview participants was done purposively. Two (2) teachers were selected respectively. In this case, the teachers that were chosen are specifically the ones that teach French at FNCC for children at beginner level. Three rounds of 45-minute interviews were conducted,

1. The first round of interview was used to gather the system requirements for the design of the mobile translator app.

2. The second round of the interview was used to demonstrate and test the beta version of the translator app to obtain feedback which further refined the design and development of the mobile translator app.

3. The third round of interview was used to test and obtain the approval of the mobile translator app from the FNCC teachers regarding its suitability as a teaching and learning tool for beginner level French for children.

The interpretive technique was followed to analyse qualitative data.

\section{TECHNOLOGY DESCRIPTION}

\subsection{The architecture of the system}

Figure 1 displays the application's architecture. The presentation, business and data layers are described in detail.

Presentation layer

This layer includes User Interface (UI) Components and User Interface (UI) Process Components (Views and Controllers). At this layer, the mobile application will be defined on how it will look on the front to its end users. The focus on the presentation is to decide the features and their location. However, simultaneously, other aspects such as font size, themes etc. are decided on this layer.

Business layer

This layer focuses on the business front. This layer concentrate on the way business will be presented in front of the end users. This includes workflows, 
Vol. 2, No. 2, September 2020

p-ISSN: 2656-5935 http://journal-isi.org/index.php/isi

e-ISSN: 2656-4882

business components, and entities beneath the hood of two sub-layers named Service and Domain model layer. The service layer concentrate on describing a common set of application functions that will be available to the client and end users, while the domain model layer represents expertise and knowledge linked to the specific problem domain.

Data layer

At this layer data related factors are focused on. This comprises of Data access components, data utilities, and service agents.

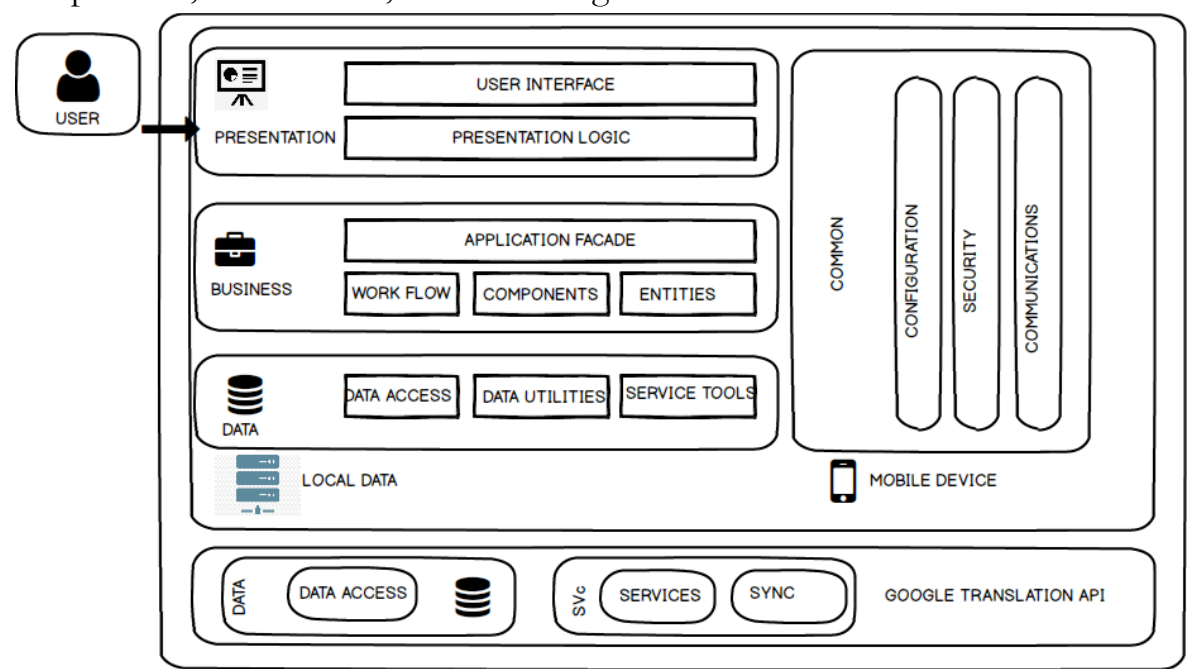

Figure 1 Mobile application system architecture (Ma, Gu, \&Wang, 2014)

One of the main service on the architecture above is the Google Translation API, this service was integrated in the application to allow the translation of text between French and English.

\subsection{The flowchart}

The diagram below shows the flowchart of the sequence of events that the application goes through when it is first opened and needs to be used by the end user. The user begins by deciding to either use the English-French translation module or use the French phrases module. The English-French module displays a visual text box whereby the user is required to input text in English, click the submit button, gets a visual display of the translation and press the sound button to generate the translated word/phrase pronunciation. The French phrases module displays different themes/categories of French phrases e.g. numbers, the user gets a visual display of sub-categories in each categories, the translated word to French is displayed as well by clicking on each sub-category and finally the user can click on the sound button to generate the translated word/phrase 
Vol. 2, No. 2, September 2020

p-ISSN: 2656-5935 http://journal-isi.org/index.php/isi e-ISSN: 2656-4882

pronunciation. If the user wants to continue with other categories, there is a back button they can click on.

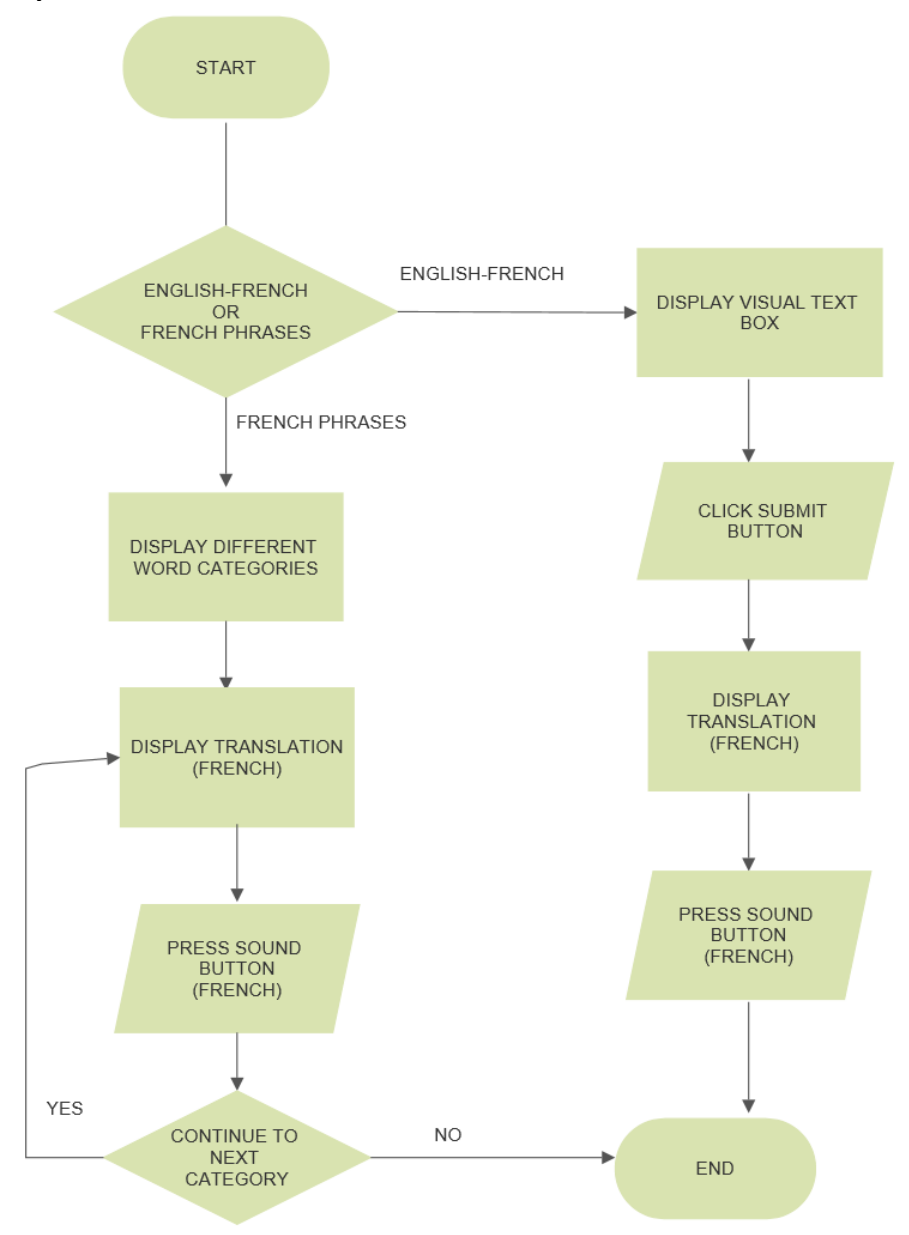

Figure 2. The system's flowchart

\subsection{The user interfaces}

Figure 3 displays the Launch page. When the user opens the application, it displays the interface below. To launch the application the user clicks on the button START.

Figure 4 displays the translation page. The user is required to type in a word or phrases and click on the SUBMIT button. After clicking on the SUBMIT button the output text will be displayed as translated. The user should click on the sound button to generate the translated word/phrase pronunciation/sound. 
Vol. 2, No. 2, September 2020

p-ISSN: 2656-5935 http://journal-isi.org/index.php/isi

e-ISSN: 2656-4882

Figure 5 displays the different themes/categories on the application. The user can navigate through all categories.
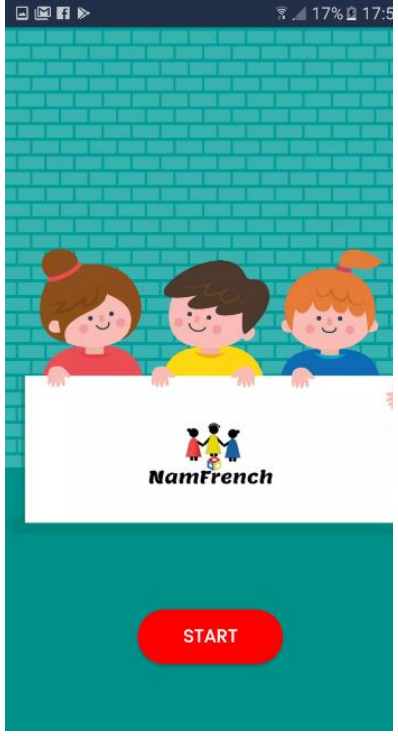

Figure 3. Launch page

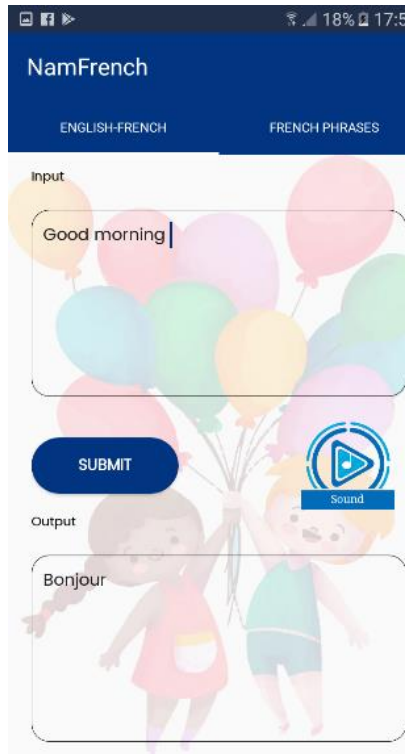

Figure 4. Translation page

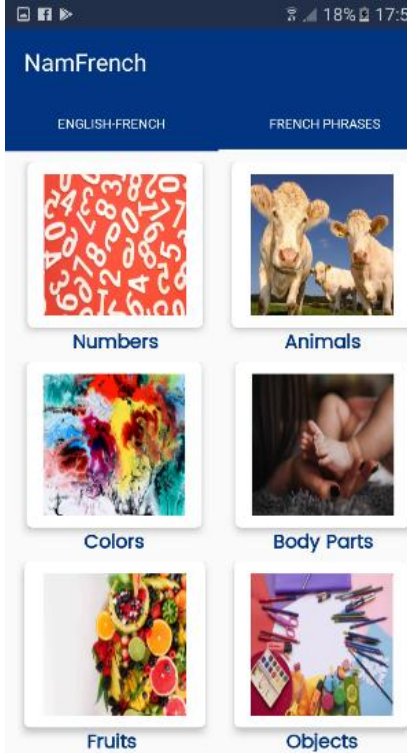

Figure 5.

Themes/categories page

\subsection{Testing}

\section{Incremental testing}

This type of testing is implemented to preliminarily assess the application at the earlier stages of its development and to provide assessment for further analysis. Each module is tested individually in unit testing phase, and then components are integrated incrementally and tested to make sure that the interface and interaction between modules is smooth. Incremental testing comprises of top down integration, bottom up integration and sandwich approach.

- Top-down approach - Testing takes place from top to bottom, i.e., from the upper module to lower module. Modules framing the top layer of application are tested first.

The top down approach was selected because architecture defects are exposed early, it outlines the working of an application as a whole in early stages and main 
control points are tested early. This type of testing was carried out by the developer as the development of the mobile application is taking place.

The beta version of the mobile application that was developed first, was tested first. Teachers were involved in this session. The feedback that was given by the participants and they were taken into consideration. The mobile application was refined, and further beta tested in the third round of interviews.

\section{DEVELOPMENTS}

The images of the preliminary design of the prototype was designed by the researcher. This phase commenced after the requirements were identified from the first round of interviews. Wireframes were initially designed to incorporate the information provided by the French teachers from the FNCC. Testing was done on the first phase of the application. The test was carried out to preliminarily assess the application at the earlier stages of its development and to provide any assessment for further analysis. All functionalities developed were tested to ensure that they meet the user requirements. This testing was done by the developer. Up to this point the application sits in a development environment that is accessible only to the developer. In this environment, the application can still get tested internally. If the testing fails, the errors get fixed. Eventually the work is complete and the final "sign off" is given that says the software fully meets all requirements. It then moves into implementation. This version of the application was installed on the teachers' mobile phones to begin with the first testing of the beta version of the application. This done until the evaluation of the mobile application take place. The evaluation tests the final version of the application against the PACMAD usability model. To develop the translator mobile application, Android Studio was used. This is an integrated development environment that provides the fastest tools for building applications for Android devices.

\section{RESULTS}

The study of [12] and [13] confirmed the existence of different theories in second language acquisition. This study indicated that teachers incorporate these theories into teaching strategies. The teaching strategies that were collected from the interviews confirms this, some strategies that were listed are writing words and phrases, reading out aloud to learn pronunciations. The study of [12] and [13] stated some teaching methods and techniques which were not part of the data collected e.g. the use of audio to learn correct pronunciation and translation of vocabulary and the usage of realistic images to teach, they formed part of the features that got included in the development of the final mobile application. The study learned the different activities used in teaching and learning French. It 
was pointed out that for reading and learning, the teachers use authentic texts with dictionaries for translation. Additionally, they allow the learners to read out loud in for improving pronunciation of words. The black board is commonly used by teachers as well to write down new words and phrases. The participants further observed that by using a range of activities it is easier to facilitate learning since learners have different learning approaches, however with learners who struggle with the language, the teacher ensures that they read answers to questions at least every single day. The main purpose for acquiring the different activities was to ensure that the mobile application is developed in a way that these activities can be performed, and additionally the learners can use the application themselves to do these activities.

The features that are incorporated in the mobile translator application were suggested by the participants. Pictures of different themes and normal translation from English to French, are important in adding value to teaching and learning French. Specific features were listed such as the normal text translation which can be used by both teachers and parents as well, sounds of words which is the pronunciation of words, flash cards and child friendly interface. An emphasis was made on how children are attracted by bright colours, the there is a high chance that a child will use the mobile translator application continuously because of the bright colourful shades they have seen. In this research, these features e.g. grammar, vocabulary, reading, writing, pronunciation, listening, speaking were incorporated to accommodate the learners and the mobile application is free for everyone noted that some translators out there have a subscription fee.

In this research habit patterns, skills and language areas were looked at in the comparison of 4 different French mobile applications using the PACMAD usability models, this was a concern in the study of [14] whereby the author called for further studies to be conducted.

The findings of this research and the study by different researchers cited in the literature in terms of benefits of mobile translator applications on foreign language teaching and learning are quite similar. It was pointed out that learners can get the required information within a short period of time, this is indeed correct because the mobile translator application can be accessed at anytime and anywhere (it can be at home) with internet connection. The mobile translator application is useful for the learners and teachers as a learning aid. With the mobile translator application, French classes are incorporating multimedia that applies motivation and provide learners with exciting new ways to learn. There are various benefits of mobile translator applications on French language teaching and learning that were listed by the participants, such as the App 
provides new learning techniques, it provides online reading, extra practice to learn more and it enhances the classroom performance.

The incremental software development life cycle worked well for this study. The mobile application was completed quickly and early and it was easier to test during the different stages. The risk of failure and changing of requirements was reduced because the requirements were collected in three different stages. The participants were involved from stage one and they could respond in each stage.

\section{BUSINESS BENEFITS}

The study discovered that there are various benefits of mobile translator applications on French language teaching and learning. The participants gave a few benefits they have encountered in their environment.

New learning Techniques - The participants indicated that the introduction of mobile translator applications in language teaching and learning has led to the introduction of new teaching techniques. They noted that there are different activities available on mobile translator applications that indulge the learners into a healthy thought process and help them understand things from a different perspective which eventually enhance learning.

Online Reading - The participants pointed out that learners are very fond of online reading, especially when the mobile application they are using is very attractive. They indicated that mobile translator applications make it easy for the learners to search for specific content in the field of language teaching and learning. They further stated learners who use these mobile translator applications potentially become more engaged, which is a good sign and it will allow them to grasp more knowledge.

Extra practice - The teachers noted that learners that attend the French language classes will be using the mobile applications for extra practice. They indicated that in order to be good in something, you need to practice more as the saying goes "practice makes perfect".

Enhances Classroom Performance - The participants indicated that mobile translator applications for language learning create an encouraging learning atmosphere. Emphasising that it enables the learners to strengthen their skills to execute school activities and other related activities with accuracy. They further concluded that the mobile translator applications boost student's confidence to a great extent.

\section{CONCLUSIONS}

This study was conducted to design and develop a mobile translator application for the beginner level children at FNCC. This study designed and developed the mobile translator application by using the incremental software development process and using the interpretivism paradigm to collect the data. The final mobile translator application was evaluated using the PACMAD usability model. The final mobile translator application will provide numerous benefits to the 
learners. The mobile translator application was specifically tailored for FNCC, it needs to be rolled out country wide for different curriculums in different schools and centres in order to find out the perspective of other teachers on French translators on teaching and learning. Issues of interoperability of the French translator mobile application across a different operating system and not only Android should be considered, e.g. iOS to allow more users to use it. The mobile translator application allows learners to use it as an extra tool for practice and it is believed to enhance teaching and learning of French at beginner level. The learners can access the mobile application anywhere and anytime with an Android smartphone

\section{REFERENCE}

[1] [Liu, X., Toki, E. I., \& Pange, J. (2014). The use of ICT in preschool education in Greece and China: A comparative study. Procedia-Social and Behavioural Sciences, 112, 1167-1176.

[2] Volman, M., van Eck, E., Heemskerk, I., \& Kuiper, E. (2015). New technologies, new differences. Gender and ethnic differences in pupils' use of ICT in primary and secondary education. Computers \& Education, 3555.

[3] Ally, M., \& Prieto-Blázquez, J. (2014). What is the future of mobile learning in education?. International Journal of Educational Technology in Higher Education, 11(1), 142-151.

[4] Alqahtani, M., \& Mohammad, H. (2015). Mobile applications' impact on student performance and satisfaction. Turkish Online Journal of Educational Technology-TOJET, 14(4), 102-112.

[5] Reid, \& P. (2016). Bring-Your-Own-Device or Prescribed Mobile Technology? Investigating Student Device Preferences for Mobile Learning. Mobile Learning Futures: Sustaining Quality Research and Practice in Mobile Learning.

[6] Ferreira, M. J., Moreira, F., Santos-Pereira, C., \& Natércia, D. (2015). The role of mobile technologies in the teaching/learning process improvement in Portugal.

[7] Godwin-Jones, R. (2011). Emerging technologies: Mobile apps for language learning. Language Learning \& Technology, 15(2), 2-11.

[8] Nushi, Musa, and Mohamad Hosein Eqbali. "Duolingo: A Mobile Application to Assist Second Language Learning." Teaching English with Technology 17, no. 1 (2017): 89-98.

[9] Fong, S. L., Elfaki, A. O., Johar, M. G. M., \& Aik, K. L. T. (2012). Investigative Study towards the Development of Mobile Language 
Translator. International Journal of Digital Content Technology and its Applications, 6(22), 11.

[10] Groves, M., \& Mundt, K. (2015). Friend or foe? Google Translate in language for academic purposes. English for Specific Purposes, 37, 112-121.

[11] Cohen, L., Manion, L., \& Morrison, K. (2013). Action research. In Research methods in education (pp. 368-385). Routledge.

[12] Altenaichinger, A. (2002). Theories of second language acquisition. In Second language acquisition: The interface between theory and practice. Summary of findings of a project-based linguistics seminar, Department of English Studies, University of Graz, Austria (pp. 8-12).

[13] Dorsteinsdóttir, H. (2014). Second Language Acquisition. The effect of Age, Exposure and Motivation (Doctoral dissertation).

[14] Steel, C. (2012). Fitting learning into life: Language students' perspectives on benefits of using mobile apps. In ascilite (pp. 875-880). 